\title{
EVALUATION OF MECHANICAL PROPERTIES OF HEMP-RAMIE FIBERS REINFORCED WITH EPOXY HYBRID COMPOSITES
}

\author{
Chandrashekar K M${ }^{1}$, Venkate Gowda C ${ }^{2}$, N G S Uduppa ${ }^{3}$ \\ Department of Mechanical Engineering, Machine Design \\ Nagarjuna College of Engineering \& Technology, Bengaluru-562110
}

\begin{abstract}
Hybrid natural composites have enlarged attention due to its light weight, low cost and low density with high strength to weight ratio and biodegradability. The substantial prominence among the structural materials has been concerned by the natural fibers. The fibers were treated with 5\% NaOH and 5\% Nacl solutions to take away the lignin content and to progress the adhesion property. In this study, the composite is fabricated by a hand layup process with different fiber orientations and also with different volume fractions. The composites are prepared with three different proportions of hemp-ramie fibers the test plates were prepared according to the ASTM standards. Various mechanical tests are conducted and also, Fast Fourier Technique (Dynamic analysis) is done to determine the frequency and damping ratio of the test plates.
\end{abstract}

Keywords: Hybrid Composite, Hand Lay-Up, Mechanical Properties And Dynamic Analysis.

\section{INTRODUCTION}

A composite material is composed of two or more micro or macro constituents that differ in chemical composition form and which are insoluble in each other. The most advanced and adaptable engineering material are composites. There is a present need for environmentally friendly, low cost materials without compromising the properties. The efforts are taken to develop new materials like composites, using natural fibers. Some of natural fibers like banana, cotton, coir, sisal, hemp, ramie, jute and bagasse have attracted the attention of scientists and technologist for application in consumer goods, low cost housing and other civil structures. Also those natural fiber composites possess better electrical resistance, good thermal and acoustic insulating properties are higher resistance to the fracture. These composites material are also used in an aerospace industry, automobile industry and other engineering applications.

P. Satish, R Keshvan [1] here the researchers investigated that the extensive use of natural hybrid composite in all almost all fields of engineering because of its advantage of having high strength, to weight ratio and biodegradability. Also the investigation of thermal and mechanical properties of banana-kenaf, glass fiber reinforced with epoxy. Hand layup process with different fiber orientation along with different volume fractions is inculcated in the study. The results of the above combinations are evaluated and samples are prepared which are tested for different mechanical properties.Girish K G, Anil K C [2] investigates about the mechanical properties of jute and hemp reinforced epoxy and polyester hybrid composites were evaluated. The fibers are placed with matrix resin in different orientations $30^{\circ}, 45^{\circ}$ and $90^{\circ}$ by simple hand layup technique. In that he observed the better mechanical properties of his study was shown in $90^{\circ}$ orientation in both epoxy and polyester based composites. Diagonal inclination of the reinforcing fibers gives poor mechanical properties as observed in $30^{\circ}$ and $45^{\circ}$ orientations composites when compared to the $90^{\circ}$ orientation.R Bhoopathi et al. [3] investigates that the role of natural and man-made fibers reinforced hybrid composite materials are growing in a faster rate in the field of engineering and technology due to its favorable properties. Here the study of banana hemp glass fiber is done by using scanning electron microscopy to obtain the different mechanical properties and morphological characteristics. Ashwani Kumar, Deepak Choudhary [4] investigates that the banana with epoxy laminate. He suggested that when banana fiber is bind with glass fiber will gives better results of the mechanical properties compare to his literature work. Also he explained that if the proportion of the fiber increases strength of the materials also increases.Tara Sen, H N Jagannath Reddy [5] investigates that the natural fibers and he used only natural fibers for making a laminate. Hence is explained that better strength of the material besides the impact compare to the tensile and bending properties of other lignocellulose fibers. 


\begin{tabular}{|c|}
\hline GFRP (Woven Roving) \\
\hline Hemp fiber \\
\hline Ramie fiber \\
\hline Hemp fiber \\
\hline GFRP (Woven Roving) \\
\hline
\end{tabular}

Fig. 1 Schematic arrangement of Hemp, Ramie Fibers

Table 1 Physical properties of materials used

\begin{tabular}{|c|c|c|c|}
\hline & Hemp Fiber & Ramie Fiber & E-glass Fiber \\
\hline Density $\left(\mathrm{g} / \mathrm{cm}^{3}\right)$ & 1.48 & $1.5-1.56$ & 2.5 \\
\hline Young's modulus $(\mathrm{GPa})$ & $30-70$ & $60-128$ & 72.40 \\
\hline Tensile Strength $(\mathrm{MPa})$ & $368-800$ & $400-1000$ & $2000-3500$ \\
\hline Elongation at break (\%) & 1.6 & $1.2-3.8$ & 2.5 \\
\hline
\end{tabular}

\section{EXTRACTION OF FIBERS 2.1 Hemp Fiber}

Hemp is one of the family member of cannabacia plant. It is an enormously beneficial plant and it provides fibers, oil also a hardwood. These kind of fibers are also used in making of rope, fishing nets, papers, fire insulating pipes and textile fiber. Hemp grows to an average of 15 feet and

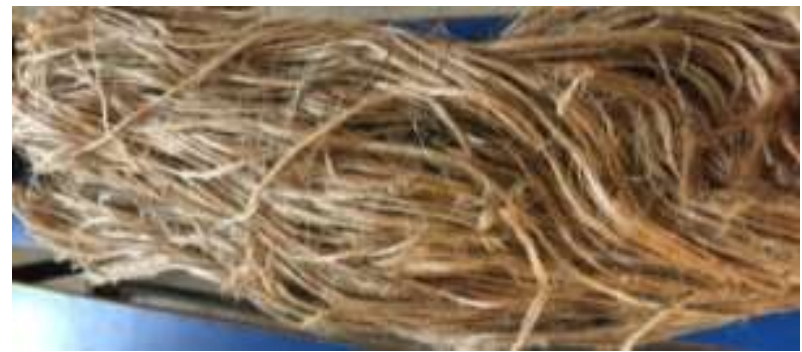

Fig. 2 Extracted Hemp Fiber

\subsection{Ramie Fiber}

Ramie is one of the oldest fiber plant and it is the king of natural fibers in the field of textile industries. Ramie is cultivated majorly in the china, hence it is well known as china grass. The plant will grows upto 12 to 15 feet high and diameter of the stem will be 12 to $15 \mathrm{~mm}$ based on the environmental circumstances. It can be easily blend with other materials due to it silky and lustrous mannerisms. These fibers are looks like whitish color also it doesnot change color when exposed to sunlight. Also repels the action of chemicals far improved than other fibers. These fibers are extracted using suitable process, the extracted fibers are shown in figure 3 .

\section{CHEMICAL TREATMENT}

The obtained fibers were treated chemically with $\mathrm{NaOH}$ and Nacl solution for the removal of lignin and pectin content. Firstly the hemp fiber was taken and washed with distilled water having $\mathrm{pH} 7$ is mixed with the $5 \%$ of $\mathrm{NaOH}$ solution which prepared after dissolving the $\mathrm{NaOH}$ pellets in the its fiber can be between 3 feet to 13 feet. It is extracted from the bark of stalk. It is twice strong as wood, bio-degradable and its fiber contain low amount of lignin. However for our requirement the hemp is extracted from the bark of the stalk by using certain process and these fibers were extracted using suitable process and these extracted fibers and the plant from which it is extracted fiber is shown in figure 2.

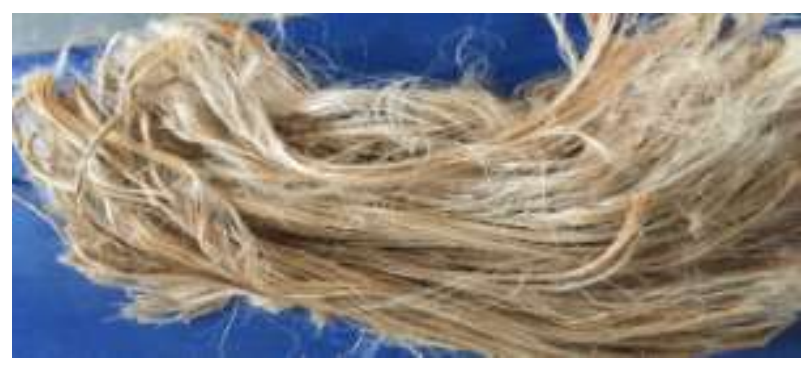

Fig. 3 Extracted Ramie Fiber

water. The same steps are repeated for the ramie fiber which is done separately for the removal of the lignin and pectin contents. The first stage of chemical treatment process is completed with the $\mathrm{NaOH}$ solution process. Now, the Nacl solution is prepared as $5 \%$ then the fibers are separately immersed in the Nacl solution and the external impurities like lignin and pectin were removed and the wet fibers were kept to dry at room temperature for 3 days.

\section{FABRICATION METHOD}

For fabrication a hand lay-up technique were used to prepare the test component specimens. Inthis process firstly, treated fibers were taken and then cut into the required orientation and lengths of the fibers were maintained and the below table shows the type of samples which were fabricated where it contents the fiber and the weight and volume fraction of fibers as shown in below table 2 . 
Table 2 Types of test specimen samples prepared

\begin{tabular}{|c|c|cc|cc|}
\hline Samples & \multirow{2}{*}{ Sequence of fiber } & \multicolumn{2}{|c|}{ Orientation } & \multicolumn{2}{c|}{ Fiber content } \\
& arrangement & Hemp & Ramie & Hemp & Ramie \\
\hline S1 & GHRHG & V & V & 55 & 45 \\
\hline S2 & GHRHG & H & H & 45 & 55 \\
\hline S3 & GHRHG & $45^{0}$ & $45^{0}$ & 60 & 40 \\
\hline
\end{tabular}

In the hand lay-up process firstly, a layer of resin is applied and then according to the orientation the fibers are kept and again the resin is applied depending upon the requirement and orientation of the fiber the number of fiber layers are kept and molded. This prepared specimen was kept in woven at $100^{\circ} \mathrm{C}$ for 2 hours. The process is repeated for remaining samples.

\section{PREPARATION OF SPECIMENS}

The test components are fabricated separately, firstly the pre mould is prepared for a dimension of $300 \times 300 \times 3 \mathrm{~mm}$ die was prepared and this plate is cut according to the dimensions of ASTM-D standards as shown in table 3 .

Table 3 Standard dimensions of test specimens

\begin{tabular}{|c|c|c|c|c|c|}
\hline $\begin{array}{c}\text { Sample } \\
\text { No. }\end{array}$ & Study & $\begin{array}{c}\text { Specimen type and } \\
\text { ASTM standard }\end{array}$ & $\begin{array}{c}\text { Length } \\
(\mathrm{mm})\end{array}$ & $\begin{array}{c}\text { Width } \\
(\mathrm{mm})\end{array}$ & Thickness (mm) \\
\hline 1 & Tensile Test & $\begin{array}{c}\text { Dog-bone } \\
\text { D- 3039 }\end{array}$ & 250 & 25 & 3 \\
\hline 2 & Flexural Test & D-790 & 125 & 12.5 & 3 \\
\hline 3 & Hardness Test & Rectangular & 80 & 50 & 3 \\
\hline
\end{tabular}

\section{COMPOSITE TESTS}

\subsection{Tensile Strength}

According to the above ASTM table the tensile test specimen was prepared. ASTM D 3039 specimen is prepared and cut using the saw cutter and the dimension of tensile test specimen standard is shown in schematic form in figure 4and the test speed of 2 $\mathrm{mm} / \mathrm{min}$.

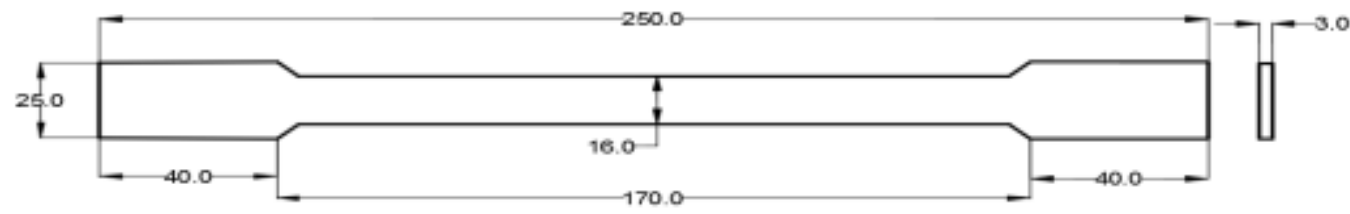

\subsection{Flexural Test}

Fig. 4Schematic diagram of tensile test specimen

According to the ASTM D 790 the flexural test specimen was calculated the dimensions of the flexural test specimen. According to the ASTM standard the schematic diagram is shown in figure 5, and the feed rate of the CNC machine is $2 \mathrm{~mm} / \mathrm{min}$.

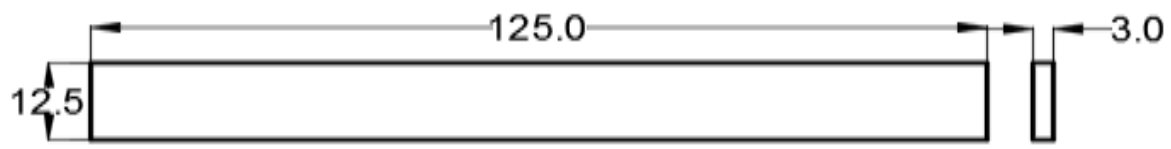

Fig. 5 Schematic diagram of flexural specimen

\subsection{Fast Fourier Test}

In this study $300 \times 300 \mathrm{~mm}$ square plate which is made with hemp-ramie and E-glass laminate with $3 \mathrm{~mm}$ thickness is used to find the damping factor. The experiment setup of the FFT has shown in thefigure 6 . The composite laminate grid is divided into $7 \times 6$ boxes, 42 points were measured over the laminate surface. Every point is taken has the single node. The specimen is clamped at one end of the plate by using the net and bolts. Care should be taken to maintain the surface equally in all the sides. Sensor is placed at the center of the surface in a laminate. Using on impact hammer the pints on the laminate are disturbed by applying the force through the hammer. The signals which are excited by disturbing the laminate at feed into the analyzer through the amplifier unit. The desired measurements points are selected and the vibration response is send to the piezoelectric accelometer once the accelometer gets the signals, the signals were conditioned in the charge amplifier and send to the analyzers. 


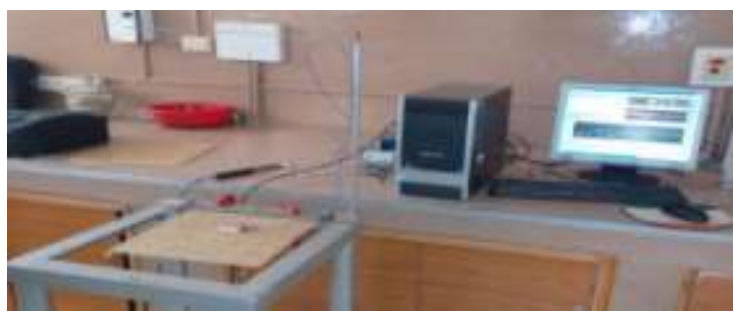

Fig. 6 Experimental step up of FFT Test

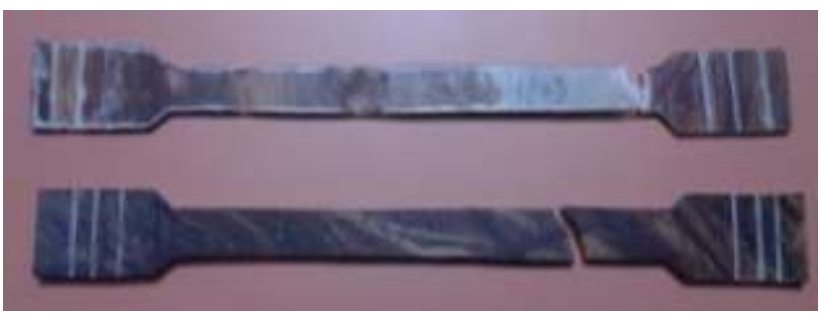

Fig. 7 Tensile tested specimen

\section{Results and Discussion \\ 7.1 Tensile Strength}

The tensile test for Hemp-ramie and E-glass epoxy hybrid composite was done and specimen is prepared for tensile test according to ASTM D 3039. The tensile strength, young's modulus and strainis determined with a load and the speed rate is $2 \mathrm{~mm} / \mathrm{min}$. The results obtained from tensile test is shown in below table 4 and graph is plotted against stress v/s strain is shown in figure 8 .

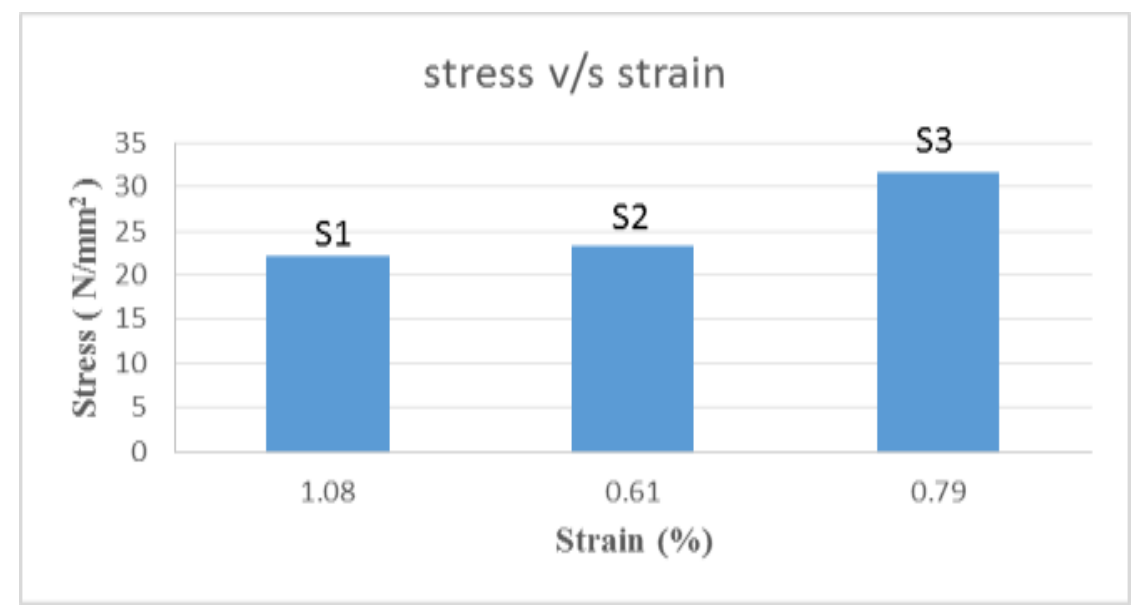

Fig. 8 Stress v/s Strain

\subsection{Flexural Strength}

According to the ASTM D 790 a hybrid composite laminate specimen was prepared to carry out the flexural test. From the test results the bending strength and maximum displacement was obtained and table 5 shows the result of 3 point bending test and the graph is plotted load v/s displacement is shown in figure 9.

Table 4 Results of Tensile Test

Table 5 Results of Flexural Test

\begin{tabular}{|c|c|c|c|c|c|c|}
\hline Samples & $\begin{array}{c}\text { Peak } \\
\text { Load } \\
(\mathrm{N})\end{array}$ & $\begin{array}{c}\text { Ultimate } \\
\text { Tensile } \\
\text { Strength (MPa) }\end{array}$ & $\begin{array}{c}\text { Young's } \\
\text { Modulus } \\
(\mathrm{MPa})\end{array}$ & Samples & $\begin{array}{c}\text { Maximum } \\
\text { Displacement } \\
(\mathrm{mm})\end{array}$ & $\begin{array}{c}\text { Flexural } \\
\text { Strength } \\
(\mathrm{MPa})\end{array}$ \\
\hline 1 & 1667 & 22.23 & 1926.29 & 1 & 3.72 & 86.50 \\
\hline 2 & 1750 & 23.33 & 3329.80 & 2 & 1.34 & 120.24 \\
\hline 3 & 2372 & 31.63 & 3980.07 & 3 & 1.43 & 142.22 \\
\hline
\end{tabular}




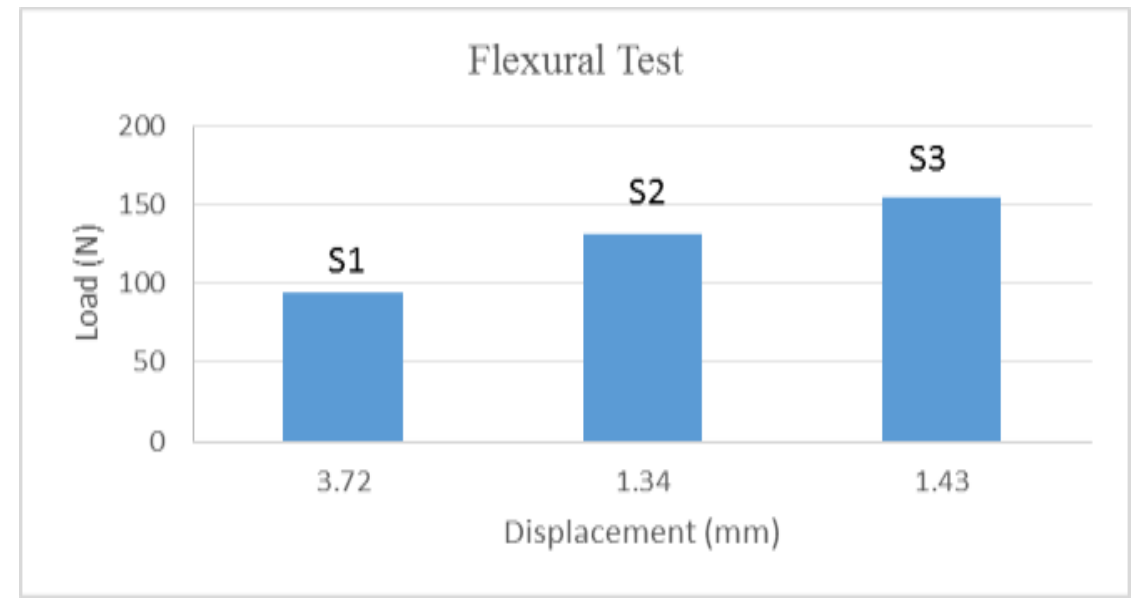

Fig. 9 Load v/s Displacement

\subsection{Fast Fourier Technique Test}

The test spacemen is considered as a cantilever beam by fixing the one end to the frame. From the experiment structural testing, reporting and analysis is done. LABVIEW software is used, to know the frequency response function (FRF) method to identify the mode shapes of the composite laminate. Table 6 shows the experimental model properties of hemp-ramie and E-glass fiber composite laminate.

Table 6 Natural frequencies and damping factor obtained from FFT test

\begin{tabular}{|c|c|c|}
\hline Types of Modes & $\begin{array}{c}\text { Natural frequency (fn) } \\
\text { in Hz }\end{array}$ & Damping factor $(\boldsymbol{\xi})$ in \% \\
\hline Bending & 25.07 & 0.807 \\
\hline Twisting & 43.76 & 0.851 \\
\hline Combination of Bending \& Twisting & 132.69 & 0.829 \\
\hline
\end{tabular}

Mode 1 (Bending), Natural Frequency 25.07 Hz, Damping Factor in (\%) 0.807

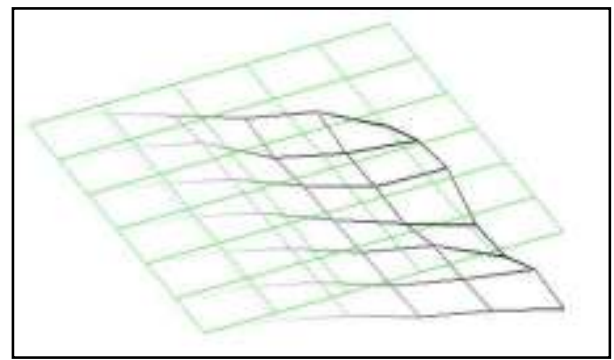

Bottom View

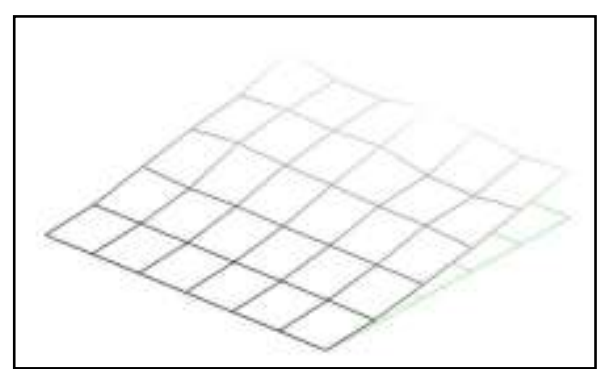

Top View

Mode 2 (Twisting), Natural Frequency 43.76 Hz, Damping Factor in (\%) 0.851

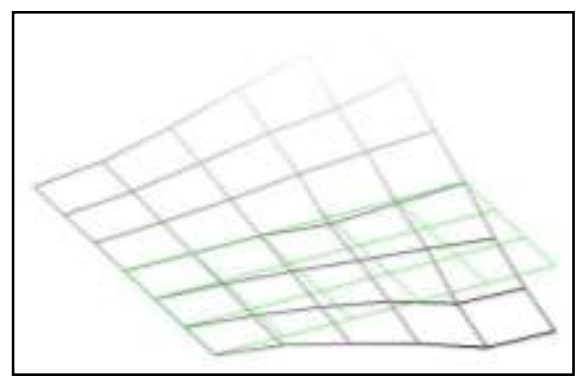

Bottom View

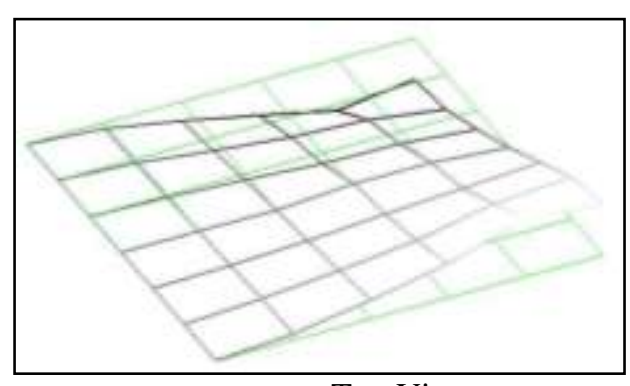

Top View 


\section{Mode 3 (Combination of Bending and Twisting), Natural frequency $132.69 \mathrm{~Hz}$, Damping factor (\%) 0.829}

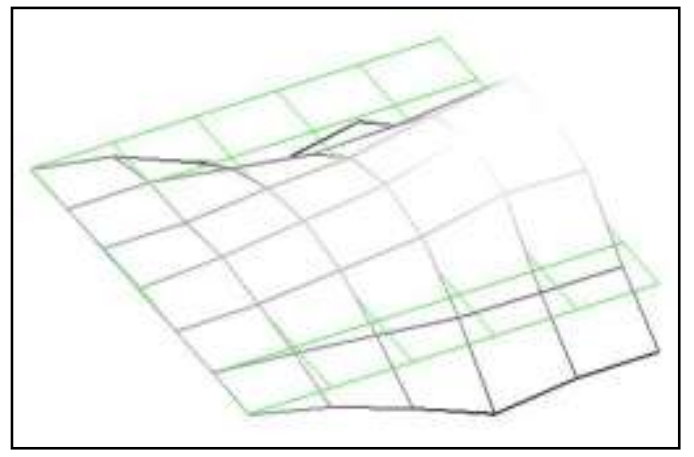

Bottom View

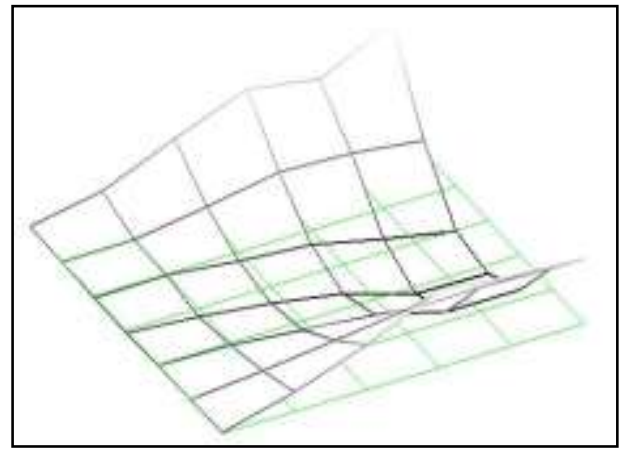

Top View

\section{CONCLUSION}

The hemp-ramie and E glass fiber epoxy hybrid composite was studied. In this study we concentrated on the base of orientations where we had done for $0^{\circ}, 90^{\circ}$ and $45^{\circ}$. The better results which was obtained was for the $45^{0}$ orientation with a fiber content of $60 \%$. The Fast Fourier technique test was also conducted and done for all the three modes in the test and the better results were obtained in this test we obtained natural frequency, damping factor and mode shapes of the sample 3 specimen.

\section{REFERENCES}

[1] P Satish, R Kesavan, B VijayaRamnath, C Vishal; "Effect of fiber orientation and stacking sequence on mechanical and thermal characteristics of Banana-kenaf hybrid epoxy composite", published in springer's, $4^{\text {th }}$ August 2015.

[2] Girisha K G, Anil K C \&Akash; "Mechanical properties of jute and hemp reinforced epoxy/polyester hybrid composites", International journal of research in engineering \& technology, ISSN 2321-8843, Vol. 2 issue 4, April 2014.

[3] R Bhoopathi, M Ramesh, C Deepa; "Fabrication and property evaluation of Banana-Hemp-Glass fiber reinforced composites", procedia engineering 2032-2041, published in ELSEVIER, 2014.

[4] Ashwani Kumar, Deepak Choudhary, "Development of glass/banana fibers reinforced epoxy composite", International journal of engineering research and applications, Vol. 3, Issue 6, pp 1230-1235, December 2013. [5] Tara Sen, H N Jagannatha Reddy, "Various industrial applications of hemp, kenaf, flax and ramie natural fibers", International journal of innovation, management and technology, Vol. 2, No. 3, pp 287-293, June 2011.

[6] M. Ramesh, K. Palanikumar, K. Hemachandra Reddy, Mechanical property evaluation of sisal-jute-glass fiber reinforced polyester composites, Composites: Part B, Vol. 4, pp 1-9, 2013.

[7] S.M. Sapuan, A. Leenie, M. Harimi, Y.K. Beng, Mechanical properties of woven banana fiber reinforced epoxy composites, Materials and Design, Vol. 2, issue 7, pp 689-693, 2006. 